\title{
Drug utilization and off-label drug use among Spanish emergency room paediatric patients
}

\author{
Cristina Morales-Carpi • Luis Estañ • Elena Rubio • \\ Empar Lurbe • Francisco J. Morales-Olivas
}

Received: 11 August 2009 / Accepted: 18 October 2009/Published online: 20 November 2009

(C) Springer-Verlag 2009

\begin{abstract}
Objective To describe the use of medicines and to determine the frequency of off-label use in emergency room paediatric patients.

Patients and methods A prospective, observational and descriptive study was carried out in the setting of the paediatric emergency room of a Spanish general hospital. Medicines used by children $<14$ years prior to their emergency room visit were analysed based on information collected from parents/guardians and relatives for each drug prescription. Off-label use was defined as the utilization of a drug at an indication, dosage, frequency or route of administration that differed from the specifications in the Summary of Product Characteristics or by children outside the authorized age group.

Results The patient cohort comprised 462 children, among whom 336 children had been prescribed 667 prescriptions. Of the medicines prescribed, $90 \%$ fell into only five 5
\end{abstract}

C. Morales-Carpi

CS Picassent, Agencia Valenciana de Salud,

Picassent, Valencia, Spain

C. Morales-Carpi $\cdot$ E. Lurbe

Servicio de Pediatría,

Consorcio Hospital General Universitario de Valencia,

Valencia, Spain

L. Estañ • E. Rubio · F. J. Morales-Olivas $(\varangle)$

Departamento de Farmacología, Facultad de Medicina y

Odontología, Universidad de Valencia,

Avenida Blasco Ibáñez 15,

46010 Valencia, Spain

e-mail: morales@uv.es

E. Rubio

Unidad de Farmacología Clínica,

Consorcio Hospital General Universitario,

Valencia, Spain
Anatomical Therapeutic Chemical Classification System groups. The most frequent active principles were ibuprofen and paracetamol. Of a total of 152 different formulations recorded, no paediatric information was provided for 40 formulations, and one formulation was contraindicated in children. Based on the established criteria, 338 prescriptions were off-label: no paediatric information or contraindication in children were available ( 82 prescriptions); the drug was used for an indication different from the authorized one (111 prescriptions); drug use was inconsistent with age recommendations (16 prescriptions); drug use was inconsistent with dose/frequency (129 prescriptions). Of the 152 formulations, 107 were occasionally used in an off-label manner.

Conclusions Although the mean number of drugs used in children is small, off-label use is frequent. Research efforts should target paediatric studies that allow a rational drug use in children.

Keywords Drug utilization study · Off-label use · Children

\section{Introduction}

Information on the effects of drugs in children is scarce due to the absence of specific trial-based data in this age group. Clinicians are therefore forced to extrapolate study data from adults. As a consequence, many drugs used in paediatric patients are prescribed without full knowledge on the optimal dosage and potential adverse drug reactions $[1,2]$.

Off-label drug use occurs when a patient receives a medicine in a manner different from that approved by the regulatory authorities, such as for unapproved indications, age groups, dosages, frequency and/or route of administration [3]. The majority of drugs in the market are not 
registered for paediatric use. Studies performed in several countries have revealed that hospitalized children frequently receive off-label drug prescriptions. A European study performed in five countries reported that $67 \%$ of the patients questioned received at least one off-label prescription [4].The percentage of patients that receive off-label prescriptions can reach up to $90 \%$ in the neonatal and intensive care wards [5]. However, this issue is not confined to hospitalized children, it is also a problem in the paediatric community setting [6].

In 2005, Pandolfini and Bonnati [7] reviewed the studies published on off-label drug use in children. They identified 30 studies published between 1980 and 2004. Twelve of these studies had been performed in community setting, but only four [8-11] recorded data in a prospective manner. The off-label prescription rate ranged from 11 to $37 \%$, but the percentage of children receiving at least a medicine in a off-label manner was up to $90 \%$ in some studies. To the best of our knowledge, there has been only one out-patient study since on this subject [12].

There are currently no data available on off-label use in the Spanish paediatric population. As most paediatric practice is provided outside of the hospital, the aim of our study was to describe the use of medicines and to determine the frequency of off-label use in Paediatric Emergency Room patients.

\section{Patients and methods}

This was a prospective, observational and descriptive study that included a random sample of children under 14 years of age who visited the Paediatric Emergency Room of the Hospital General Universitario de Valencia, Spain (HGUV) during a 14-month period (from June 2005 to August 2006). Oncological and human immunodeficiency virus (HIV) patients were excluded from the study. HGUV is a tertiary hospital that covers a population of 350,000 inhabitants, of which 46,000 are children $\leq 15$ years of age. The patient sample was randomized by first selecting 6 days per month and then selecting six patients on each day. Random number tables were employed for both procedures.

The medicines that the children were receiving prior to their emergency room visit were registered in a data entry sheet that had been designed to collect general patient data (age, sex, weight, reason for consultation) and detailed information for each drug prescription (indication, dose, frequency and route of administration). Self-medication was also registered. The information was collected from an interview with parents or relatives and was always performed by one of the authors (CMC). The medications received were classified according to the International Anatomical Therapeutic Chemical (ATC) Classification index, and they were assessed as to whether they had been used according to the terms of the Summary of Products Characteristics $(\mathrm{SmPc})$. We considered off-label use to be the utilization of a drug at an indication, dosage, frequency or route of administration different from those specified in the $\mathrm{SmPc}$ or in children outside the authorized age group. A $\pm 10 \%$ difference in dosing between the data obtained and $\mathrm{SmPc}$ was tolerated when determining the off-label status for the dose. We also considered off-label use when the $\mathrm{SmPc}$ did not specifically provide paediatric information. In terms of the prevalence of drug use of $50 \%$, a sample size was obtained with a $\pm 5 \%$ precision and a significance level of 0.05 . The required number of patients was 381 children.

The statistical analysis used the Student's $t$ test with a significance level of $p<0.05$. Comparisons of proportions were made using chi-squared tests $\left(\chi^{2}\right)$, with the results expressed as relative risk (RR) and 95\% confidence intervals (CI). Although this was a noninterventional study, information was given to parents or relatives, and their authorization was required. The study protocol was approved by the ethics committee and the institutional review board of HGUV.

\section{Results}

A total of 462 children [ 237 boys and 225 girls; average age 5.2 \pm 3.7 (95\% CI 4.9-5.6 years)] were included in the study (Table 1). Of these, 336 children had received drugs prior to the emergency room visit. Table 2 shows the characteristics our pediatric study cohort. During the third quarter (from July to September), the percentage of children

Table 1 Age and sex distribution of the paedriatic study population

\begin{tabular}{llll}
\hline Age & Girls $(n)$ & Boys $(n)$ & Total \\
\hline$<1$ year & 19 & 33 & 52 \\
1 year & 29 & 34 & 63 \\
2 years & 24 & 27 & 51 \\
3 years & 9 & 17 & 26 \\
4 years & 31 & 25 & 56 \\
5 years & 25 & 19 & 44 \\
6 years & 15 & 20 & 35 \\
7 years & 8 & 7 & 15 \\
8 years & 17 & 12 & 29 \\
9 years & 15 & 12 & 27 \\
10 years & 12 & 7 & 19 \\
11 years & 9 & 8 & 17 \\
12 years & 8 & 13 & 21 \\
13 years & 4 & 3 & 7 \\
Total & 225 & 237 & 462 \\
\hline
\end{tabular}


Table 2 Characteristics of patients that received and did not receive drugs

\begin{tabular}{lll}
\hline Characteristics of patient cohort & Received drugs & Did not receive \\
\hline Number $(\%)$ & $336(72.7)$ & $126(27.3)$ \\
Age, mean $(95 \%$ CI) & $5.0(4.6-5.4)^{*}$ & $5.9(5.2-6.6)$ \\
Sex (M/F) & $176 / 160$ & $61 / 65$ \\
$<4$ years (\%) & $80.2^{* *}$ & 19.8 \\
$>4$ years $(\%)$ & 67.4 & 31.6 \\
\hline
\end{tabular}

${ }^{*} p<0,05$ compared to those that did not receive drugs; ${ }^{* *} p<0,05$ compared to children $>4$ years

that received drugs decreased $(59 \%)$ relative to the other three quarters (first, 78.3\%; second, 77.2\%; fourth, 76.0\%).

A total of 667 drug prescriptions involving 161 different active principles and 152 formulations were registered.

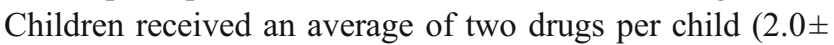
1.1 , range 1-7). The most frequent active principles were ibuprofen $(152,22.8 \%)$, paracetamol $(134,20.1 \%)$, amoxicillin (41, 6.2\%), salbutamol $(27,4.1 \%)$, dextromethorphan $(18,2.7 \%)$, domperidone $(16,2.4 \%)$ and montelukast $(16$, $2.4 \%$ ). The 79 most commonly prescribed active principles covered $90 \%$ of all prescriptions. The majority of drugs were administered by oral route $(86.2 \%), 5.5 \%$ by inhalation, $3.6 \%$ by topical application and $3.4 \%$ by the rectal route.

Figure 1 shows the therapeutic classes most often prescribed according to the ATC classification. Drugs for respiratory diseases $(\mathrm{R})$ were the most prescribed $(26.5 \%)$,

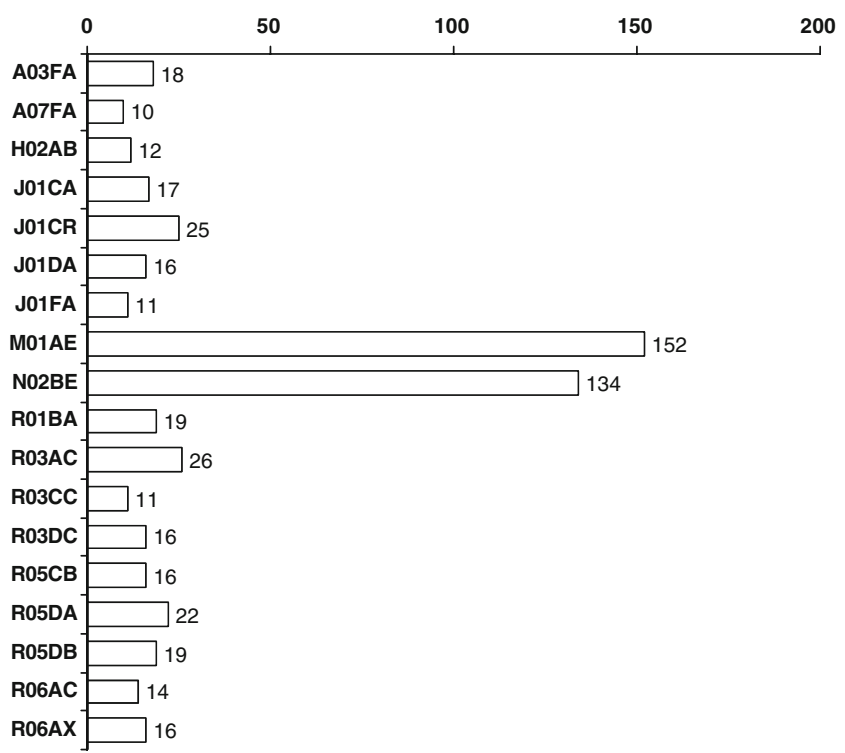

Fig. 1 Therapeutic classes (International Anatomical Therapeutic Chemical Classification System) of drugs most often prescribed. $R$ Respiratory group, $M$ musculoskeletal system group, $N$ nervous system group, $J$ anti-infective for systemic use group, $A$ alimentary tract and metabolism group, $H$ systemic hormonal preparations, exclusive sex hormones and insulins followed by those for the musculoskeletal system group (M), which contains ibuprofen (23.8\%), the nervous system group $(\mathrm{N})$, which contains paracetamol $(22.8 \%)$, the antiinfective for systemic use group $(\mathrm{J})(10.6 \%)$ and the alimentary tract and metabolism group (A) (10.0\%). The qualitative prescription profile was similar for each quarter analysed, but the utilization of drugs of the $\mathrm{R}$ group was higher in the first and fourth quarter $\left(\chi^{2}=12.25, p<0.01\right)$.

The most common indications for which drugs were prescribed were fever (210 cases), cough (67 cases) and upper respiratory tract infections ( 66 cases). The majority of the prescriptions $(56.7 \%)$ had been written by paediatricians; $34.3 \%$ of the prescriptions, affecting 168 patients, were self-medications; $7.7 \%$ of the prescriptions were written by general practitioners; $1.2 \%$, affecting eight patients, were based on the advice of pharmacists.

Of the 152 different medicines recorded, 111 (73\%) were authorized for paediatric use. Of these, 45 (29.6\%) were authorized without restrictions, $59(38.8 \%)$ had an age restriction and seven (4.6\%) had a weight restriction. No specific information for paediatric patients was provided for 40 formulations $(26.3 \%)$, and one formulation, containing acetylsalicylic acid, was contraindicated in paediatric patients. Thus, $26.9 \%$ of the drug formulations were necessarily for off-label use.

Of the 667 prescriptions recorded, 338 (50.7\%) were offlabel (Fig. 2, Table 3). No drug had been used by a route other than that authorized. Of the 152 different medicines, $107(70.4 \%)$ had occasionally been used in an off-label manner (Fig. 2).

A total of 228 children $(67.9 \%$ of those that received medicines) received off-label drugs, with $41.9 \%$ receiving one off-label drug, $18.8 \%$ receiving two drugs and $6.5 \%$ receiving three drugs (Fig. 2). There were no significant differences in mean age or distribution by sex among children in different situations of drug use.

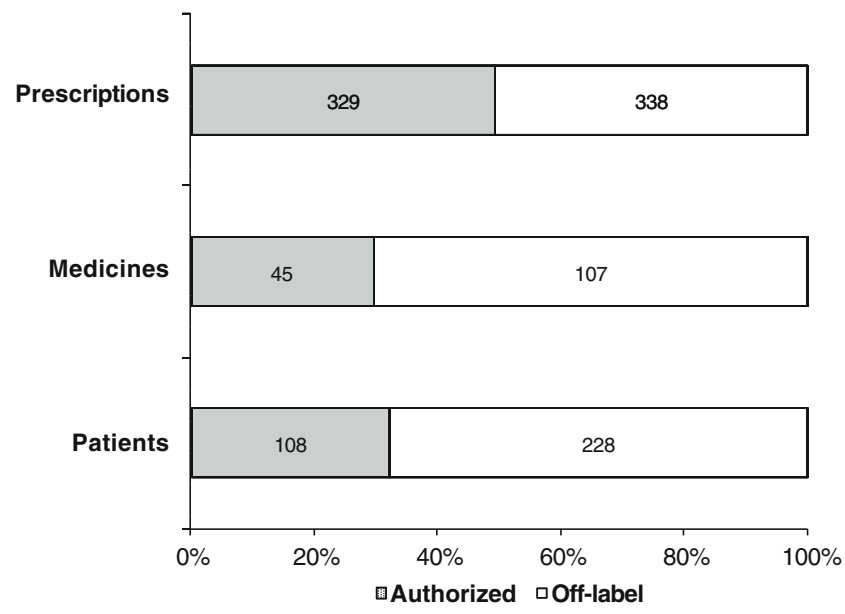

Fig. 2 Off-label use affecting prescriptions, medicines and/or patients 
Table 3 Causes of off-label use

\begin{tabular}{lll}
\hline Type of off-label use & Children $^{\mathrm{a}}(n)$ & Prescriptions (\%) \\
\hline Lack of paediatric information & 74 & $82(24.3)$ \\
Different indication & 94 & $111(32.7)$ \\
Different age & 15 & $16(4.7)$ \\
Different dose or frequency & 108 & $129(38.1)$ \\
\hline
\end{tabular}

${ }^{a}$ One child may be included in more than one group

The ATC groups that were most frequently used off-label were: R (31.4\%), N (23.1\%), M (16.6\%), A (13.6\%) and J $(8.3 \%)$. Of the total number of drugs recorded, $70 \%$ of those included in group A, $60 \%$ of those included in group $\mathrm{R}$ and $50 \%$ of those included in group $\mathrm{N}$ were used in an off-label manner. The most commonly prescribed off-label drugs were paracetamol and ibuprofen (Fig. 3).

The majority of the off-label prescriptions $(54.4 \%)$ were from paediatricians; $34.3 \%$ were self-medication, $9.8 \%$ of the prescriptions were from general practitioner and $1.5 \%$ was from pharmacists.

\section{Discussion}

This is the first study to analyse off-label drug use in a Spanish paediatric community setting. The only earlier study performed in Spain was a retrospective study in hospital setting, so the results are not comparable to those presented here [13]. Our study shows that off-label drug use was a common practice in our paediatric population, and as such, our results are similar to those described in previous studies performed in the USA and Europe [3, 4, 7, 12].

We found that seven out of ten children that visited in the Paediatric Emergency Room of our hospital had already received drugs. These results are in agreement with those reported by other authors in Italy [14]. The average number of drugs per patient is also similar to that observed in an European study, including Spanish paediatric community patients [15]. The mean number of drugs found in our study is small, which reflects the trend of drug prescription shown in recent studies [8-11]. It must be pointed out the fact that the percentage of children that received drugs decreased in summer, although the number of drugs received did not. This observation supports the recommendation of including the season of the year in which such studies are performed in order to be able to compare the pattern of drug prescription [16]. Consequently, one should be cautious when extrapolating the results of other studies because seasonal variations in the types of diseases and prescriptions may be present [8].

More than half of the prescriptions received by the children enrolled in our study were off-label, with more than three-quarters of the children receiving at least one offlabel drug. We found a higher percentage of off-label use than has been reported in other prospective studies [8-11]. The percentage of our children affected by off-label use was lower than that reported by Chalumeau et al. [8] in a study that included a sixfold larger sample, but it was higher than that found in other studies [9-11]. These differences may be explained by the fact that the concept of "off-label" is not the same in all studies. We have tried to be exhaustive when defining off-label use and have included every situation that could be considered as off-label use, even so far as considering the use of drugs with no specifically provided paediatric information in the SmPc as off-label. This latter situation is called "unlicensed" by a number of other authors [17]. In this sense, efforts should be made to obtain a consensus on common definitions for off-label and unlicensed uses and incorporate this consensus into European legislation [18].

Although based on a first analysis the difference between the results of this study and those from other studies could be attributed to the high percentage of self-medication, offlabel use in the self-medication group was similar to that observed in the group of children who received their prescriptions from paediatricians. If the prescriptions of drugs without paediatric information were excluded, the percentage of off-label use would be $38 \%$, which more closely resembles the percentage reported by Chalumeau et al. [8]. Another aspect that could explain the differences is the Hawthorne effect [19] in those prospective studies in which paediatricians collect the information. An example of this is when the paediatrician feels that the prescription is going to be analysed by a third party and, therefore, modifies his/her prescribing behaviour.

Most of the ATC groups were affected by off-label use, but the most frequent ATC group was the R drug group,

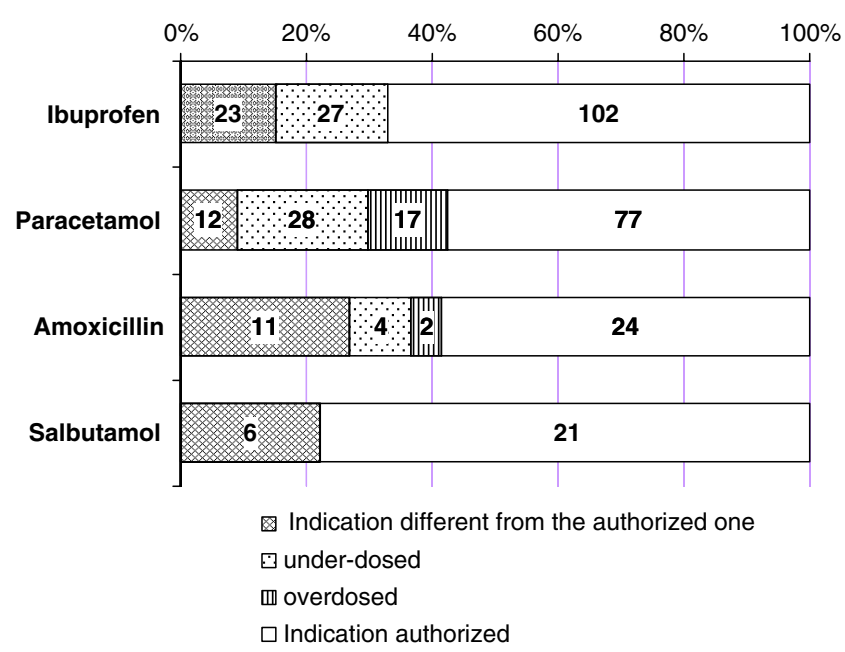

Fig. 3 Most commonly prescribed off-label drugs 
which was also the most frequently ATC prescribed group. When the percentage of off-label use was analysed for each ATC group, we found a higher off-label use of the A group of drugs due to the fact that the most part of drugs for which there is no paediatric information belong to this group. This result agrees with the study of Pandolfini et al. [9].

The most frequent reason in our study for defining drug use as off-label use was incorrect dosage. This is in accordance with the results of other studies, both retrospective $[7,20]$ as well as prospective [11]. Again, different criteria for defining off-label may influence the conclusion (s) reached by the researcher(s). We found a higher percentage of incorrect dosage among the $\mathrm{N}$ and $\mathrm{M}$ groups of the ATC classification.

Our study has its limitations. Although our sample can be considered to be representative of the paedriatic patients that visited the emergency room of HGUV $(2.5 \%$ of the total of patients visited in this period), we cannot establish that it is a representative sample of the general population. However, this limitation may be counteracted by the fact that, according to the National Health Survey, more than $80 \%$ of the population visits an emergency room at least once a year and that our study covers a 14-month period. A second limitation could be the information sources, which were the parents or guardians. These individuals may have inadvertently provided inaccurate information on doses and/or drug indication by referring to the real use of drugs rather than the original prescription. However, some authors have considered the interview method to be more advantageous than those that collect information from databases and medical records [21].

Although off-label drug use is not synonymous with inappropriate or illegal use [22], some studies have demonstrated an increased risk of adverse drug reactions [10]. Occasionally, off-label use is induced by the recommendations from repertories and guidelines. The information included in these sources is not always supported by clinical evidence due to the lack of paediatric clinical trials. This lack of paediatric information leads to each prescription being an uncontrollable experiment. In contrast, information may be available from clinical paediatric research, but it information is not included in the SmPc $[23,24]$. Research efforts should target paediatric studies that allow a rational drug use in children. The recent approval of European regulation on medicinal products for paediatric use [25] should facilitate paediatric clinical research and may improve rational drug use in children.

What is already known on this topic?

- There is little information currently available on the effects of drugs in children; thus many drugs used by paediatric patients are prescribed in an off-label manner.

- No data are available on the frequency of off-label use in Spanish paediatric community setting.
What does this study add to the current body of information on this topic?

- Off-label use is a common practice in the Spanish paediatric population.

- More than half of the prescriptions received by the children in our study were off-label.

- Off-label use in self-medication was similar to that observed in prescriptions from paediatricians.

- More than three-quarters of the children of our study received at least one off-label drug.

- There are seasonal variations in the use of drugs in children

Funding None

Competing interests None

\section{References}

1. Morales-Olivas FJ, Morales-Carpi C (2006) Clinical trials in children. Rev Recent Clin Trials 1:251-258

2. Pandolfini C, Impicciatore P, Provasi D, Rocchi F, Campi R, Bonati M (2002) Off-label use of drugs in Italy: a prospective, observational and multicentre study. Acta Paediatr 91:339-347

3. Cuzzolin L, Zaccaron A, Fanos V (2003) Unlicensed and off-label uses of drugs in paediatrics: a review of the literature. Fundam Clin Pharmacol 17:125-131

4. Conroy S, Choonara I, Impicciatore P, Mohn A, Arnell H, Rane A et al (2000) Survey of unlicensed and off label drug use in paediatric wards in European countries. European network for drug investigation in children. Br Med J 320:79-82

5. Turner S, Longworth A, Nunn AJ, Choonara I (1998) Unlicensed and off-label drug use in paediatric wards: prospective study. $\mathrm{Br}$ Med J 316:343-345

6. McIntyre J, Conroy S, Avery A, Corns H, Choonara I (2000) Unlicensed and off-label prescribing of drugs in general practice. Arch Dis Child 83:498-501

7. Pandolfini C, Bonati M (2005) A literature review on off-label drug use in children. Eur J Pediatr 164:552-558

8. Chalumeau M, Tréluyer JM, Salanave B, Assathiany R, Chéron G, Crocheton $\mathrm{N}$ et al (2000) Off-label and unlicensed drug used among French office based paediatricians. Arch Dis Child 83:502-505

9. Pandolfini C, Campi R, Clavenna A, Cazzato T, Bonati M (2005) Italian paediatricians and off-label prescriptions: loyal to regulatory or guideline standards? Acta Paediatr 94:753-757

10. Horen B, Montastruc JL, Lapeyre-Mestre M (2002) Adverse drug reactions and off-label drug use in paediatric outpatients. Br J Clin Pharmacol 54:665-670

11. Lifshitz M, Gavrilov V, Grossman Z, Binsthok M, Hornik D, Rosemblum $\mathrm{H}$ et al (2002) Unapproved prescription practices in primary pediatric clinics in Israel: a prospective analysis. Curr Ther Res Clin Exp 63:830-837

12. Bazzano AT, Mangione-Smith R, Schonlau M, Suttorp MJ, Brook RH (2009) Off-label prescribing to children in the United States outpatient setting. Acad Pediatr 9:81-88

13. Danés I, Vallano A, de la Cruz G, Juárez JC, Arnau JM (2002) Utilización de medicamentos y condiciones de uso recomendadas en pediatría. An Pediatr (Barc) 57:414-419

14. Cazzato T, Pandolfini C, Campi R, Bonati M (2001) Drug prescribing in out-patients children in Southern Italy. Eur J Clin Pharmacol 57:611-616 
15. Sanz E, Hernandez MA, Ratchina S, Stratchounsky L, Peiré MA, Lapeyre-Mestre M et al (2004) Drug utilisation in outpatient children. A comparison among Tenerife, Valencia, and Barcelona (Spain), Toulouse (France), Sofia (Bulgaria), Bratislava (Slovakia) and Smolensk (Russia). Eur J Clin Pharmacol 60:127-134

16. Martínez-Mir I, García-López M, Palop V, Ferrer JM, Rubio E, Morales-Olivas FJ (1999) A prospective study of adverse drug reactions in hospitalized children. Br J Clin Pharmacol 47:681-688

17. Turner S, Nunn AJ, Choonara I (1997) Unlicensed drug use in children in the UK. Paediatr Perinatal Drug Ther 1:52-55

18. Neubert A, Wong IC, Bonifazi A, Catapano M, Felisi M, Baiardi P et al (2008) Defining off-label and unlicensed use of medicines for children: results of a Delphi survey. Pharmacol Res 58:316-322

19. McCarney R, Warner J, Iliffe S, van Haselen R, Griffin M, Fisher $P$ (2007) The Hawthorne effect: a randomised, controlled trial. BMC Med Res Methodol 7:30

20. Ekins-Daukes S, Helms PJ, Simpson CR, Taylor MW, McLay JS (2004) Off-label prescribing to children in primary care: retrospective observational study. Eur J Clin Pharmacol 60:349-353
21. Headley J, Northstone K (2007) Medication administered to children from 0 to 7.5 years in the Avon Longitudinal Study of Parents and Children (ALSPAC). Eur J Clin Pharmacol 63:189195

22. Hoppu K (2008) Paediatric clinical pharmacology-at the beginning of a new era. Eur J Clin Pharmacol 64:201-205

23. Schirm E, Tobi H, de Jong-van den Berg LT (2003) Risk factors for unlicensed and off-label drug use in children outside the hospital. Pediatrics 111:291-295

24. Morales-Carpi C, Estañ L, Torró I, Lurbe E, Morales-Olivas FJ (2006) ¿Son los niños hipertensos españoles huérfanos terapéuticos? An Pediatr (Barc) 64:114-119

25. Regulation (EC) No 1901/2006 of the European Parliament and of the Council of 12 December 2006 on medicinal products for paediatric use and amending Regulation (EEC) No 1768/92, Directive 2001/20/EC, Directive 2001/83/EC and Regulation (EC) No 726/2004. Available at: http://ec.europa.eu/enterprise/ pharmaceuticals/eudralex/vol-1/reg_2006_1901/reg_2006_1901_ en.pdf. Accessed 17 July 2009 